Journal of Education and Educational Development

7(2), 216-243, 2020

DOI: http://dx.doi.org/10.22555/joeed.v7i2.143

\title{
Human Rights Education and Language Learning in Pakistan: An EFL Perspective
}

\author{
Tazanfal Tehseem \\ tazanfal@ymail.com \\ University of Sargodha, Pakistan \\ Zahra Bokhari \\ bokharizahra@gmail.com \\ University of Sargodha, Pakistan \\ Saba Zulfiqar \\ zulfiqarsaba8@gmail.com \\ University of Lahore, Pakistan
}

\begin{abstract}
This paper explores the dissemination of human rights through English language learning in Pakistan and builds on the knowledge that contributes to the development of democratic educational outcomes. Textbook discourses have long been the domain of critical linguistics; critical linguists understand textbook discourse primarily as a language in the context of schooling while the discourse analysts understand such discourses as systems of knowledge and ideology. The question of how the learners are expected to engage with the subject knowledge is explored from two theoretical perspectives: linguistic analyses are executed using tools such as choice of pronouns, mood, and modality from Systemic Functional Linguistics (Halliday et al., 2014), a social semiotic theory of language as a meaning potential, and reinterpreted according to the intercultural paradigm (Piller, 2010) to familiarize the ways interactants choose to build relations in the textbook narratives because in exploring interpersonal meanings it is very easy to focus on what is said and why. Additionally, the image analysis is done by representational analysis that of how images reflect ideologies (Kress \& Van Leeuwen., 2006). The contributions of this study are of particular importance to
\end{abstract}


make visible elements of interpersonal meaning-making which were explored in the context of cumulative knowledge building in humanities.

Keywords: critical linguistics, human rights, ideology, systemic functional linguistics, textbooks

\section{Introduction}

Human rights education motivates respect, dignity, and appreciation for human beings, provokes equality, and significantly contributes to decision making among the youth. Such traits play an important role to prevent conflicts that may arise among humans. That is why there is a dire need to promote human rights education to help the youth become responsible citizens to build a peaceful society. However, besides so many efforts made during the past decades, literacy outcomes have not been affected especially in schools.

Broadly speaking, human rights are the norms and principles which are universally accepted and are the same all over the world. Human rights are to be provided with honesty as a violation of any of the human rights can mark an individual as criminal and he can be punished according to international law. When we go for human rights in education that simply leads to the fact that education must promote these values for sure in children. They must be inculcated with these values through learning a language. Language has the power to construct ideologies and it has the power to shape our thinking. This kind of education is fruitful for the children to realize what human rights are and how they can bring this notion into action in their practical lives. So language learning plays a vital role in disseminating and propagating values.

Despite the need, both pedagogy and the language learning content did not focus much on the value of education. Partially because the senior school students face grade issues in their final years of schooling (Freebody, 2007; Schleppegrell, 2004). So to meet their high aims senior school students show the least interest in the ideological content being taught to them and show much concern towards assessment practices for achieving high grades. Therefore, the main focus comes to primary school teachers to address the need (Freebody, 2007). Hence, the textbooks which are selected for language teaching are aimed to effectively promote skills 
and literacy regarding value loaded education with an assumption that those literacy practices will continue throughout years of living.

Various desirable skills can be inculcated in learners by educating them on human rights (Totten \& Pedersen, 2011). In today's world where human rights violations occur abundantly, human rights education can serve as a means to prevent future violations as it helps individuals to construct and propagate a universal human rights culture (Kukovec, 2017).

\section{Background of the Study}

The history of liberal and enlightened education in Pakistan has been controversially related to literary education. Over the decades, that has been debated around practices from curriculum to pedagogy. With the emergence of linguistic studies in Pakistan, there have been vibrant researches in the educational field, for example, Emi et al., (2013); Mahboob (2009) to quote a few. It is impossible to be aware without having training or education regarding human rights therefore, UNESCO's focus since after World War II, is only on the promotion of human rights through language learning and other education. In this regard, UNESCO in 1993 enacted a commission named 'The Dalor Commission on Education of Twenty-First Century'. That commission aimed to explain upcoming inclinations in education policy that comprised of knowledge, its implication in living together, and to be a good human being. It was thought that these key points are basic poles of the education building.

World program for human rights education is agreed that human beings pose socio-political, economic, and cultural rights to develop. It shows that freedom is the base of all human rights so freedom must be ensured. Having freedom means that one should be free in choice in all aspects of life and should have the liberty to spend life the way one wants. According to the language and social power project, the children are made to talk explicitly about language in form of their writing tasks (Martin et al., 2008). Therefore, the textbooks are responsible to inculcate particular beliefs in the minds of the students. The texts have a complete system of language that represents the entire meaning potential inherent in the language (Halliday et al., 2004). So, to probe the theme the textbooks supporting language learning have been analyzed to see whether those promote human rights content. 


\section{Research Questions}

The study focuses on the following research questions.

1) How do EFL textbooks promote human rights education in Pakistan?

2) Does the EFL teaching inculcate specific social values to Pakistani learners?

The study makes some significant contributions to the vast repertoire of academic knowledge based on the research questions given above. It helps to better understand what academic literacy and its implications mean to primary education in Pakistan. In doing so the study explains how the content exploited expresses interpersonal meanings to bridge the gap identified. Also, it helps to understand literacy shifts needed to improve pedagogical practices in language teaching.

\section{Literature Review}

Several studies have been carried out to significantly probe different literacy requirements of the learners in their school years, see, for example, Becher and Trowler, 2001; Bernstein, 1990; MacDonald, 1994 and Maton, 2014 to quote a few. Therefore, the literature available in this field is vast, but based on the objectives of this study we only focus on the contributions reflecting the social value of education. It is worth mentioning that we find many significant contributions to value-laden education from Sociology (Bernstein, 1990). We find the nature of academic knowledge produced significantly contributes towards promoting social education based on human rights education (Bernstein, 1990).

Besides, Flowers et al. (2000) presented a view that Human Rights are some rights that one possesses is a human being regardless of being male, female, infant, boy, girl, rich and poor. However, Cates (1990) discusses human rights in terms of global education and explains it as an awareness that provokes peace, skill, and a sense of responsibility regarding life in territory that has multiple shades of culture and customs. He introduces 'linguapax' (i.e. peace through language), a project by UNESCO. Linguapax suggests that teachers must focus on effective language learning for the promotion of human rights through which awareness of international understandings will be increased.

United Nations (2012) declaration gave some activities to promote human 
rights among students of primary and secondary level. At first, the basics and objectives of human rights have been discussed whereas the awareness of these rights has been argued later through games, activities, etc. Geneva's (2012) declaration proposed guidelines for governments to inculcate human rights through education. It was suggested that the Government should do situation analysis or self-monitoring analysis based on output. It should make some policies in the education field to project human rights. On the other hand, Starkey (2002) stated that democracy, peace, human rights, and sustainable developments are interlinked with one another and make a circle of living together. The study proposes seven lesson plans to promote seven human rights in children through education including the right of social security, earning, respect for children's rights, and the right to have the religion of your own choice. Starkey indicates with the reference of linguapax that education has an agenda to inculcate respect for others' cultures and basic human rights. It is one of the important factors to give rise to democracy to live in a multicultural community. However, in the Pakistani context Mahboob (2009) conducted a study through gender analysis and highlighted that although English is a foreign language it also promotes Islamic values and sensitivities about the Pakistani context.

Similarly, Christie et al., (2010) examined the Pitjantjatjara community (uncivilized) and argued that education and literacy help make people civilized. Whereas, Torres (2012) researched EFL textbooks of Norma series called Clapping Time applying semantic analysis proposed by van Dijk (1993) and found the implicit content those books portrayed the children not as citizens or the participants of society but as subjects who have got no rights. However, Zolkos (2006) proposed some assumptions about the use of language in discursive functions of human rights and concluded that language has the power to challenge social discriminates.

It is worth noting that human rights education is much more than simply imparting theoretical knowledge. According to Struthers (2014), through formal education, respect for those rights ought to be promoted among young learners. This can be possible only if the humanistic approach is adopted in classrooms through a conducive learning environment. Educating learners about human rights makes them responsible for their actions with a focus on personal growth, and show respect for differences while developing a sense of harmony, equality, freedom, and 
respect (Kukovec, 2017).

Based on the review, there is an academic requirement to look into the content being exploited for language teaching in Pakistan, with an appreciation of interpersonal meanings portrayed in the selected texts.

\section{Methodology}

The data for the study comprises nine texts carefully selected from the EFL textbooks published by Oxford University Press, Pakistan. The data is selected on the parameters of human rights education especially the texts which promote interpersonal meaning potential. The sophistication in expression was the prime focus for making selections which is 'of the crucial importance in humanities. Further, the study builds on content analysis. The books were taken from the middle classes. The analysis aims at proving the working hypothesis that EFL textbooks promote human rights education. The study has been designed to show how English language learning in Pakistan is promoting human rights and values and influencing the minds and thought patterns of the students. The represented data indicates that the English language is promoting human rights education to make the youth capable of making this world peaceful and livable. The content analysis of the paper is based on the framework explained below.

Piller's (2010) model of 'Intercultural communication in a Multilingual World' refers to the idea that language learning can inculcate values as these choices are logically and economically embedded. Speakers make linguistic choices from the language they have access to which is known as linguistic diversity. These choices then are responsible to shape our thinking accordingly.

This research wields a multimodal discourse analysis approach put forward by Kress and Van Leeuwen (2006) based on Systemic Functional Linguistics of Halliday (1994). The discourse of multimodality analyzes images in the texts through three Meta functions.

i. Representational meanings

ii. Interactional meanings

iii. Compositional meanings 


\section{Representational Meanings}

It refers to 'the content or potential ideas, stories, and concepts represented in a multimodal ensemble' (Serafini, 2013). Representational meaning focuses on representation and ideology in the image. The representational process is bifurcated into two processes, the Narrative process, and the Conceptual process. The narrative process is further branched as an action and reaction process based on participant and kind of vector. Vectors are imaginary lines that make the image more explicable by directing the attention toward the prominent component in the image. Contrary to the narrative process, the conceptual process does not employ vectors. It is further split into three processes; Classification process, analytical process, and symbolic process.

\section{Interactional Meaning}

It refers to the relationship between the represented participants (objects or participants in an image) and the viewers (Serafini 2013). Interactional meanings are characterized by four aspects;

i. Gaze

ii. $\quad$ Size of frame

iii. Perspective

iv. Modality

Gaze studies the eye contact between participants and viewers. Based on gaze a picture can be a 'demand' picture or 'offer' picture. If the gaze is towards the audience it makes the picture demanding and if the gaze is a way it's an offered picture. In the second part, the size of the frame determines the social distance between represented participants and viewers. Three kinds of shots are used in the size of the frame:

i. Close shot

ii. Medium shot

iii. Long shot

A close shot takes the image of the participants from a short distance focusing on the head and shoulders. It implies an intimate relation between participants and viewers. While the medium shot takes an image of the participant up to the waist, showing social relations between participants and viewers. Long 
shot suggests an impersonal relation taking an image in full length till toe of the participants or from a long distance.

The third aspect, perspective is recognized by two different camera angles.

i. Horizontal angle

ii. Vertical angle

iii. A horizontal angle results in a frontal plane having maximum involvement of participants and viewers. The vertical angle helps to develop a power relation between participants and viewers

\section{Compositional Meaning}

It refers to 'the spatial organization of elements and the framing devices that connect and separate these elements in multimodal ensembles' (Serafini, 2013). Compositional meanings are characterized by three aspects:

i. Information value

ii. Salience

iii. Framing

Information value is the endowment of specific informational value to various elements in a visual discourse according to the zone of their location (Tehseem, 2017). It is further split into three designs; new-given, ideal-real, center-margin.

In the new-given layout, the components presented on the left side along a horizontal axis are called 'given' which are already known. On the other hand, components on the right side along the horizontal axis are 'new', that is, the constituents that are yet to be discovered. In ideal-real structure, the constituents of the image in the upper section are considered as 'Ideal', which are highly valued. The constituents in the lower section are 'real' and are of less value and low status than ideal. Salience deals with the degree of attention captured by the participants or components of the image due to their size and color contrast. The third aspect framing deals with the connection of participants with each other in the image. Lines and color sharpness are some of the framing devices.

Hence, employing this methodology images in the texts are analyzed, and texts are analyzed using Piller's model of cultural communication. 
Framework of the Analysis

\begin{tabular}{|c|c|c|}
\hline Sampling & Content Analysis & $\begin{array}{c}\text { Perspective of } \\
\text { Multimodal Analysis }\end{array}$ \\
\hline $\begin{array}{l}\text { This section includes } \\
\text { different samples of the } \\
\text { data from the textbooks } \\
\text { taken to be analyzed } \\
\text { further following the } \\
\text { dimensions of Piller's } \\
\text { model (2010). }\end{array}$ & $\begin{array}{l}\text { The section of content } \\
\text { analysis is based on the } \\
\text { linguistic evidence and } \\
\text { lexical choices used in the } \\
\text { samples of the data. }\end{array}$ & $\begin{array}{l}\text { The section on } \\
\text { multimodal analysis helps } \\
\text { further in analyzing the } \\
\text { foregrounded elements } \\
\text { and features in the } \\
\text { samples of the data. }\end{array}$ \\
\hline
\end{tabular}

\section{Criteria for the Selection of Data}

The data selected for the analysis is based on the promotion of human rights. The selected text is inquisitive for human rights i.e. liberty, peace, shelter, food, freedom, and tolerance, etc.

\section{Findings}

This study is based on content analysis with the help of Piller's model (2010). The samples that are presented are showing that human rights are deep-rooted into the texts and are responsible for the promotion of these values. UNESCO has introduced peace through language in which teaching and learning should be incredibly effective to promote human rights. Human rights education is of great worth as it is a way to teach students about their rights as well as what rights they have to give to others. To get the sense of equality, freedom, and independence they need to be taught slowly and gradually because these kinds of changes do not come overnight. For this, syllabuses are to be maintained with these kinds of values and while learning a foreign language, i.e. English language students must learn what human rights are.

\section{Education}

(Pg. 7, book 5, Oxford New Modern English)

\section{Linguistic Evidence}

Learning is a treasure, good education, and personal wellbeing, school-age child, why education is so important, social classes, development, and human 
rights.

Piller's (2010) concept views that the choice of lexical items used in the text is an attempt to promote education as a human right and to make it an intricate belief of the students.

\section{Interpretation of the Related Text}

\section{Title}

Text 1 with the title 'Education' (Unit 2) is written in the bold case and the background includes different equations that further emphasize advancement and the need for education.

\section{Subtitle}

Why is education so important?

It ends with the question mark which shows that the text is further going to analyze the advantages of education and its importance in the present world.

\section{Use of Semiotic Resources (showing children in classrooms)}

The attention of the students is grabbed by various uses of images which in result would attract them towards education. The text is logically combined with the catchphrases along with the use of different semiotic resources.

In the image on the top left corner (image: 2) one of the students is raising his hand to answer the question. A soft smile on the teacher's face shows a positive gesture, encouraging the students to participate in the class activities.

In image 3, one of the students is writing on the board. This promotes the right to education through a positive gesture shown in the image that education is a birthright of every individual. Similarly, the images on the right side of page 2 show students doing group study, which promotes education all these pieces of evidence show that English texts view education as a right of every individual of the society, and is following human rights values. 


\section{Use of Proverbial Phrases}

The right side of part 1 of the text includes a Chinese proverb 'Learning is a treasure that will follow its owner everywhere' (Unit 2), followed by an image of a man carrying an empty basket on his back going towards the place where he could find treasure. Such representations would urge the students to admit the importance of education.

\section{Use of Rhetorical Questions}

The $2^{\text {nd }}$ part of the text from Unit 2 starts with the catchphrase 'How is good education provided'?

It is further supported by the presentation of images of different situations in the classrooms. On the top left corner of the page, a student is shown completely involved in writing in his notebook content following this image shows the right to education. This shows that English texts regard education as a guarantee for students' development.

\section{An Insight to Social Panorama (A Widening Perspective of the Prestige of all Social Classes)}

The social classes shown in the images are presented with the idea that education is a basic necessity of life. The adherence of every individual, irrespective of his/her social class and background, towards education shows that education is realized as a basic human right that should be granted to every individual. Hence, EFL texts inculcate the idea that education is not just a property or possession of elite classes but is a right of everyone.

\section{Visual Analysis of Image 2}

i. Representational analysis. This narrative representation includes a transactional auction process where the raised hand of a representative participant attracts viewers. It makes viewers speculate that the participant wants to ask a question. The teacher performs as an actor and the student as a goal. The smile on the face of the Actor is directed to the goal as a gesture of appreciation.

ii. Interactional analysis. This image forms a relationship between 
participants and viewers. This image is a kind of offer image directing the gaze of participants away from the viewers. This is a medium-size shot representing the social distance between participant and viewer. While taking in view the perspective horizontal angle, the frontal and vertical angle is eye level angle representing equality between the viewer and the participant.

iii. Compositional analysis. The image enhances the value of education with the opened book and raised the hand of the participants. The participants are the point of focus in the image. Clock and apple act as an auxiliary in the image portraying the importance and value of time for education Participants are the salient parts of the image.

\section{Obama's Interview}

(Pg. 10, book 6, Oxford New Modern English)

\section{Linguistic Evidence}

Government education policies improve the education system, administration, more money in training good teachers, to improve how schools are operating, importance of education, importance of staying in school, dropout prevention programs, parents role to ensure children's better education, parents teachers consultation, child's performance, fruits, and vegetables in school, work hard and succeed.

According to Piller's (2010) model, linguistic choices are specified. The choices selected to make up a text are discourse specific. These choices are responsible for promoting human rights education.

\section{Interpretation of the Related Text}

Text 2 shows the views of Obama regarding education given in an interview with Damon Weaver. The American president is one of the most authoritative persons on earth. A presentation of his views in the school textbook clearly shows that English courses promote education as a right. One of his comments is given below: 
"I am going to be making a big speech all across the country about the importance of education and the importance of staying in the school" (text 2, pg. 30)

\section{Use of Personal Pronoun 'I': Advocating Personalization (Emphasizing Education for All)}

This statement shows his concern for education to be gained at all levels. He is of the view that education is the birthright of every child.

\section{Introducing Government Training and Policies}

The text is supported by introducing government training and policies to make the educational system more advanced.

\section{Dropout Prevention Programs by the President}

The inclusion of these kinds of programs shows that the schools are stabilized by providing federal government funding to local school districts.

\section{Parent's Role in Children's better Education}

The text also includes a parent's role in promoting education. They have to set the standards and aim high for the children so that they could enter the school with high morals.

\section{Parents Teachers Consultation Programs}

These kinds of programs provide a chance for both parents and children to work in close association with the moderated by opinions of teachers.

Visual Analysis of the Image

i. Representational Analysis. This image is a kind of Narrative process image. The represented participants in the image form a narrative discourse comprising of the reaction process. In this image, the eyes of the participant are making vector. Participant (President Obama) who is being interviewed about education acts as a Reactor attentively directing his gaze on the interviewer who acts as a phenomenon.

ii. Interactional Analysis. Through the interactive analysis, it is evident 
that there is no direct gaze between represented participants and viewers. It forms an offered picture as the gaze is away from the viewer. The frame is a medium shot. The horizontal angle of the participants is oblique and the vertical image is eye level equal. It shows the relation of equality.

iii. Compositional Analysis. Concerning information value, a center-margin structure is adopted. The importance is given to the participant who is being interviewed about education as a human right. The interviewee is a salient part of the image because his viewpoint is of the main concern, and his size in terms of Rank is of high value. T, there is no dividing line between the represented participants which shows the connection between characters.

\section{Nelson Mandela's Views Regarding Education}

(Pg. 42, book 5, Oxford New Modern English)

\section{Linguistic Evidence}

Nature was our playground, large smooth rocks which we transformed into our roller coaster, learned a lesson from an unruly donkey, Africans have a highly developed sense of dignity, to humiliate another person is to make him suffer an unnecessarily cruel fate, he should go to school, no one in my family had ever attended school, the youngest son should go to school.

Piller's (2010) concept supports these lexical choices as accountable for promoting human rights specifically education.

\section{Interpretation of the Related Text}

Emphasis on education through Eminent figures of the World. Text 3 represents the World's eminent leaders who promote education and to make students realize it's worth is an indicator that they promote education as a right. Nelson Mandela clearly states that education is the only way to progress as it plays a vital role. To get the name and fame in the world. 
Use of Historical References. The narration of Nelson Mandela's school and his approach towards study projects his concern for the development of education and peace in the world.

Use of Symbolic Imageries through Narration. The text uses the incident of an unruly donkey as symbolism to learn a lesson through it and motivates the students towards the importance of learning.

Use of Declarative. The use of declarative sentences like He should go to the school and his youngest son should go to the school, show that the text contains the relevant factors to emphasize school going and learning.

A Shift to Literate Population. The text advocates the advancement of the state through literacy. The literate population makes the country more peaceful, so the text supports the promotion of education which is a very basic human right.

\section{Visual Analysis of Image}

i. Representational Analysis. The image of Nelson Mandela represents a conceptual process. It forms a symbolic process as it tells the reality of the participant. the meaning and identity itself. The picture of Nelson Mandela foregrounds these aspects.

ii. Interactional Analysis. This is a demand picture making an intimate relationship with the viewer about the gaze. This demand picture invites the viewers to know about the views of Mandela about Human rights. From the point of the size of the frame, it is a Medium shot indicating the social relationship between represented participants and viewers. The horizontal angle is frontal rather than oblique, from the point of perception. This shows the level of involvement between the participant and viewers. Vertical angle maintains the equality between the represented participant and viewers by eye-level shots.

iii. Compositional Analysis. From the point of information value, this image is center margin, which represents the image of Mandela in the center so it is also a salient part of the image. There is no framing used in the picture. 


\section{Being free}

(Pg. 51, book 6, Oxford New Modern English)

\section{Linguistic Evidence}

United Nations Declaration of Human Rights (1948), we are all born free and equal, we all have our thoughts and ideas, we should be all treated in the same way, this human right is a great aspiration, those who are not free long to be free and those who are free do not appreciate their freedoms.

Piller's (2010) concept adheres to these choices as properly schematized for the texts to promote freedom.

\section{Interpretation of the related Text}

Referencing. The text refers to the past in which a bill was passed for the observation of human rights. The text also refers to the book The Social Contract (1762) by a social reformist and naturalist, Jean -Jacques Rousseau.

United Nations Declaration of Human Rights (1948). Text 4 shows the severe condition of man as reflected through his image in chains which is indirectly conveying a particular message about freedom. Freedom is necessary to live your life according to the freedom granted to you. It involves freedom of expression, freedom of thought, and freedom of action which enable a person to lead his/her life freely in a society. Contrarily, if you are put into chains, and if you merely follow the dictates of others, survival would become impossible.

Use of Slogans. The use of catchphrases like:'

We all are born free and equal. We all have our thoughts and ideas. We should all be treated in the same way.' Show that the students are made to reflect on the concept of freedom and its importance for them.

Use of quotation. The quotation 'Man is born free, but everywhere he is in chains' by Jean- Jacques Rousseau emphasizes the importance of freedom as a Human Right in the text. 
Repetition of the word 'Free'. The text is replete with the word 'Free' and 'Freedom' and it makes students ponder upon the importance of freedom and create in them the importance of education as a human right. The repetition of the word, 'free' in the text makes it a coherent piece of writing.

Depiction of Political Strategic Conditions. The text includes strong political references showing the importance of freedom for a nation and at an individual level too. For instance, if we see the image on the title page the remorseful expressions of the man who is chained show the worth of freedom at the individual las well at the national level.

Use of Imperatives. The first article of human rights stated that all men are born equal, are free, and have their ideas and thoughts, so they should be treated as free individuals. The imperative mood is used to challenge the orders.

Use of Metaphor. The word 'chain' is used as a metaphor that refers to socio-economic chains. These chains are worse than physical chains. The image in the text symbolizes the mental and physical chains and side by side signifies freedom and the necessity for human rights Education.

Use of Questions. On the lower right corner, in a box, some questions are given to make the reader reflect on the significance of freedom and to explore more aspects of the need for freedom.

\section{Visual Analysis of Image}

i. Representational Analysis. The image of Nelson Mandela represents a conceptual process. It forms a symbolic process as it tells the reality of the participant. the meaning and identity itself. The picture of Nelson Mandela foregrounds these aspects.

ii. Interactional Analysis. This is a demand picture making an intimate relationship with the viewer about the gaze. This demand picture invites the viewers to know about the views of Mandela about Human rights. From the point of the size of the frame, it is a Medium shot indicating the social relationship between represented participants and viewers. The horizontal angle is frontal rather than oblique, from the point of 
perception. This shows the level of involvement between the participant and viewers. Vertical angle maintains the equality between the represented participant and viewers by eye-level shots.

iii. Compositional Analysis. From the point of information value, this image is center margin, which represents the image of Mandela in the center so it is also a salient part of the image. There is no framing used in the picture.

\section{Secret Country}

(Pg. 21, book 7, Oxford New Modern English)

\section{Linguistic Evidence}

A desire for peace and social equality, equality of opportunity, space of freedom, the idea of a free country, It's a good country, It's a secret country, It's a kind country, there are no prisons, there are no poor, there are no weapons, there is no war, It's a safe country, in that country grows a great tree, and it's called freedom, and its fruit is free, which is your country and mine.

Piller's (2010) model inspects that the use of specific vocabulary is a deliberate effort to inculcate the values and human rights education among the students.

\section{Interpretation of the Related Text}

Use of Semiotic Resources (An Emphasis on Peace and Social Equality). Text 5 shows how a country should be. A concept of a unique country is projected which focuses on the concept of freedom. The use of different words like no cages, no zoo, free creatures, and no prison indicate that freedom is focused. It is of the view that there will be an ideal country and the public will enjoy freedom without paying any cost. Enhancing the concept of freedom as a human right shows that the English language is concerned with human rights development and is inculcating these values in the minds of students.

Use of Foregrounded Elements. The repetition of lines "it's a secret country and it's your country and mine" is foregrounding the rest of the text. Lexical choices in the repetition of lines distinctly emphasize the need for human rights education. 
Use of Adjectives. There are many adjectives used with the word "country" making it more explicable like a good country, secret country, kind country, a strange country, a safe country, a warm country, a loving country, and a blue country. Some other adjectives in the poem are free creatures and great trees. Excessive adjectival use in this text is the deliberate choice of words to stress the importance of human rights education.

\begin{tabular}{l|c|l} 
Attributive adjectives & Positive adjectives & Negative adjectives \\
\hline Good country & $\checkmark$ & \\
\hline Secret & $\checkmark$ & \\
\hline Kind & $\checkmark$ & \\
\hline Strange & $\checkmark$ & \\
\hline Safe & $\checkmark$ & \\
\hline Warm & $\checkmark$ & \\
\hline Loving & $\checkmark$ & \\
\hline Blue & $\checkmark$ & \\
\hline Free creatures & $\checkmark$ &
\end{tabular}

The table shows the frequency of positive adjectives that are employed to disseminate human rights education.

Use of Personification. In the selected text Freedom is personified as a growing great tree whose fruits are free which everyone can relish. . The choice of words creates the image of the tree growing and proliferating its branches far and between, representing the ever-increasing growth of freedom.

Referencing. Ragamuffin, a character of medieval mystery plays is referred to in the text to highlight the fact that it is the country of all, of the poor and the rich. Everyone is free in this country. The secret country belongs to even ragged clothed children without any discrimination.

Use of Refrain. "It's a secret country, and it's your country and mine" is used as a Refrain at the end of every stanza to emphasize the fact that it is a country where everyone can live freely as it belongs to everybody. 


\section{Visual analysis through Multimodality}

i. Representational analysis. This Conceptual discourse constructs a concept of prayer. Prayer to have such a country where everyone can live according to one's own will. This conceptual representation consists of a symbolic process. This symbolizes hope and a positive attitude.

ii. Interactional analysis. Keeping in consideration the size of the frame this is a close shot focusing only on hands and the raises originating from them. As far as perspective is concerned, the horizontal angle is frontal and the vertical angle is eye level.

iii. Compositional analysis.

\section{If the only Papa hadn't Danced}

(pg. 78, book 3, Oxford New Modern, English)

\section{Linguistic Evidence}

Trying to cover her tears, this is our homeland, metal coil which uncoiled like a snake, rings of wire, wire with teeth could slice the clothes from your back, the skin from your bones, his tools were at his feet, a pistol in his belt, Beware of crocodiles, finally you are in the city, and can be swallowed up by all people there, a house with the white flowers, I saw papa dance.

Piller's (2010) concept assesses the use of specific lexical choices to promote the right to education and freedom.

\section{Interpretation of the related Text}

Text 6 promotes the right to freedom. It shows that freedom is the prime necessity to make ourselves independent. The symbolic use of many words is actually to reach to the actualization of what is freedom.

Use of Symbols. White flowers represent peace and freedom as they get refuge after getting freedom. Crocodiles are also symbolized as those entities which did not allow the family to live freely in the country. The character 'Papa' is saving his family from these ferocious crocodiles.

Use of Adjectives. The selection of adjectives in the text is to enhance the dissemination of human rights education e.g. Shallow and splashed water, Tawny 
hills, metal fence, ferocious jaws, giant cutting tool, and safe house.

Depiction of Hypersensitive Incidents. Crocodile's depiction elucidates the whole design of danger and proclivity of freedom. The inclusion of this text in the syllabus seems to inculcate the education of human rights in the students. The impact of this education is enhanced by the incorporation of such incidents and words.

Simile. The fence along with the border is mentioned: 'Like a snake', 'fence like a scorpion'. It shows the venomous attributes of fences which have dividend the people of the world and abducts the freedom of movement.

Mood: Use of Imperatives. Most of the poem is in declarative mood narrating the experience of the family related to freedom; whereas, dialogues are in the imperative mood. Few of the lexical choices and mood of the sentence are given here.

"Wait here", Papa said.

It is a kind of order to save the family from any danger. Similarly:

'Take me', Papa begged him 'Spare the woman and the girl'. This sentence is a kind of request as it shows self-sacrifice for the family to give them the happiness of freedom.

"Hurry", He said.

"You go first", Papa said to me. "I want you to be the first in my family to taste freedom".

Here lexical choices of "Go First" and "Taste freedom" are used as culturally embedded expressions. These words are of great importance in a society where freedom is a great treasure and a fruit of exquisite taste.

\section{Feeding the World}

(Pg. 72, book 6, Oxford New Modern English)

\section{Linguistic Evidence}

Feeding the world, enough food, Chinese proverb, thousands upon 
thousands of fruits, abundant, variety of eatables to show the resources of food in the world for example fruits, vegetables, meats, fish, spices, herbs, and grains.

Piller's (2010) model views the deliberate use of lexical choices used in the title 'Feeding the World' to promote human right education. These choices are economical??? Embedded.

\section{Interpretation of the related Text}

Text 7 promotes the right to food, clothes, and shelter, which are basic human rights. The title page includes a proverb 'Give me a fish and I eat for a day; teach me to fish and I eat for a lifetime' is focusing on the concept of earning a livelihood by honest means. To provide others with skills rather than just food is a better service. It has a link to the very basic human right that is food. To eat healthy food is a basic necessity of life.

Title. Feeding the world refers to the need for food, poverty, and hunger prevailing in the world. The title is deliberately chosen to show food as a basic need in the world.

Subtitle. How can we make sure that there is enough food for everyone?

Referencing. Some countries are referred to in the text, such as Korea, Brazil, and Malawi to throw light on the importance of food as a basic need. French Italian and Dutch paintings are also referred to in the text.

Use of proverb. Chinese proverb is employed in the text to emphasize the importance of livelihood earned through struggle. The choice of this proverb stresses the importance of hard work and struggle in the minds of the students. Proverb says;

'Give me a fish and I eat for a day, teach me to fish and I eat for a lifetime'.

Mood. The complete narrative is in a declarative mood.

Use of Questions. Questions on the right corner of the page are raised to make students think about the resources of the world and the basic human rights of the 
provision of food. A Chinese proverb suggests struggling to earn a livelihood.

\section{Visual Analysis of the Image}

i. Representational analysis. This image represents a conceptual process that makes the image coherent with the proverb. The concept of fishing is distinct in the image.

ii. Interactional Analysis. The image interacts with the viewers through nature. The picture is a demand picture that invites viewers to explore it. As far as the size of the frame is concerned, it is a long shot that depicts the view of a lake, boat, and trees.

iii. Compositional analysis.

\section{What is it like Not to Have Enough to Eat}

(Pg. 31, book 7, Oxford New Modern English)

\section{Linguistic Evidence}

What is it like to not have enough food to eat? People picking over the rubbish heap, reuse, hunger, people starving in countries suffering from famine, how droughts have destroyed farmers' crops, and created food shortages.

Piller's (2010) concept of Intercultural Communication marks these texts as widely open and challenging for the students to focus and pay attention to quality education. These kinds of texts have deep positive effects on the thinking of the students.

\section{Interpretation of the related Text}

Text 9 promotes the right to food. It is a basic necessity of life to eat healthy food. Showing the condition of starvation even in the big modern cities of the world is satirical. Food is highly linked with the right to live and to help others. These kinds of lessons are aimed at making students realize and actualize the worth of food and how it feels when one is in a state of starvation. The text-only shows the value of helping others. 
Dual Meaning Word. The word 'Forage' is deliberately used in the text as an ideologically contested word. Forage for animals is employed in the text as;

Animals forage for food

The same word for human beings is employed as;

Human forage in rubbish heaps when they are desperately hungry.

\section{The Red Rooster}

(Pg. 47, book 5, Oxford New Modern English)

\section{Linguistic Evidence}

More equally, is an ideologically contested word which refers that resources are not distributed equally so the lexical choice 'more equally' is used to emphasize the need for equal distribution of resources.

Frowned, it is a culturally embedded expression and depicts that nothing is better than humans in the world.

'Her husband frowned at her'

Resources, folk tales, rich old father, medicine man,

These choices are determined to promote human rights education among children. The choices are economically embedded with a specific agenda to promote values and peace in the world. These kinds of texts are highly beneficial for students. The implicit working of these kinds of texts would influence the minds of the students and they would learn about values (Piller, 2010).

\section{Interpretation of the related Text}

Text 13 promotes the right to unity and projects values i.e. brotherhood. This story advocates living together, as man is a social animal. He cannot survive alone, he needs to build and maintain relationships to share his feelings with others. Living together demands affiliation. The use of the word 'brother' is symbolically promoting a sense of brotherhood. The last lines read: 'Of course I forgive you 
because we are brothers', shows the text is promoting a sense of brotherhood as a right to have healthy relations.

Referencing. Ethiopia is referred to in the text in the background, referencing it for poor resources and poverty.

Advocating Brotherhood. The text advocates brotherhood and a spirit of self-sacrifice to save the life of others. As the younger brother says;

If my brother needs it, he must have it.

The red rooster was the only property he had but he gave it to save the life of his brother. Such type of discourse in ELT books is aimed at inculcating human rights education in students and to make them aware of the spirit of brotherhood, love, and peace as basic human rights. It promotes unity, tolerance, and ethical values.

\section{Use of adjectives}

\begin{tabular}{l|c|c} 
Attributive adjectives & Positive adjectives & Negative adjectives \\
\hline Rich old father & $\checkmark$ & \\
\hline Kind & $\checkmark$ & \\
\hline Good-hearted & $\checkmark$ & \\
\hline Younger son & $\checkmark$ & \\
\hline Fine red feather & $\checkmark$ & \\
\hline Red rooster & $\checkmark$ & \\
\hline Rich brother & $\checkmark$ & \\
\hline Big rooster & $\checkmark$ & $\checkmark$ \\
\hline Tasty stews & $\checkmark$ & $\checkmark$ \\
\hline Proud & & \\
\hline Selfish & & $\checkmark$ \\
\hline Elder son & $\checkmark$ & \\
\hline Sick man & &
\end{tabular}

The frequency of positive adjectives is more than negative adjectives. It unveils the lexical choices made to propagate human rights education.

The mood of sentences. The entire discourse is made of declarative and imperative moods. Narration is in the declarative mood but dialogues are switching moods 
from declarative to imperative and vice versa. The following are some of the examples of declarative mood.

'It can't be helped', "the younger brother said to his wife. No doubt he needs all the grains for himself",

"You won't get better"

No, but your brother has said his wife.

'Then go and ask my brother to give it to me'

Your elder brother's ill, She said

'And the only thing that can cure him is the flesh of a big rooster with fine red feathers'

Some of the selected imperative sentences are given:

Ah well, he is still my brother after all

I haven't got a rooster, the sick man cried.

That horrifying thing!

Slaughter a cow (order)

Make a feast (order)

Let's celebrate my recovery (suggestion)

As seen from the data analysis, EFL books are playing a vital role in social cohesion and are contributing to the propagation of moral values. It is found that foreign language learning is playing a critical role in endorsing human rights, and the choice of lexico-grammatical features help to construct peace ideologies. Therefore, we can say that English language learning in Pakistan helps to promote human rights. In this way, students can effectively learn a foreign language and are also empowered with civic sense and social application.

\section{Conclusion}

The world has witnessed horrible consequences of World War II, and this has raised a need for the promotion of human rights education to sustain peace. Therefore, we have examined themes in EFL textbooks promoting human rights. The study has found that such themes are present in general discussion in content and are emphasized through pedagogy. The content included themes like conflict resolution, social skills, and civil movements for freedom, peace education, and 
appreciation of multiculturalism. Literacy and pedagogical practices remained under hot discussion in Pakistan for several decades (Mahboob, 2015). Unfortunately, those debates were politicized and did not bring any significant results on legitimizing human rights pedagogies. But their demand increased for the professional training for the ELT practitioners, especially in schooling to help understand pedagogies that inform and influence human rights education. Therefore, the study has significantly contributed to creating awareness among language teachers about the content they teach in schools. As referred above in the subsequent sections, the study has raised the awareness of the material writers about the content to help the learners know how they can engage with the interpersonal meaning potentially reflected in textbooks. Also, the study has highlighted the demands for construing an interpersonal stance in the content compatible with the society we live in. Therefore, understanding knowledge structures can cumulatively build appreciation and respect for harmony and freedom.

\section{References}

Becher, T., \& Trowler, P. R. (2001). Academic tribes and territories: Intellectual enquiry and the cultures of disciplines. (2 ${ }^{\text {nd }}$ ed.) Open University Press.

Bernstein, B. (1990). Class, codes and control, the structuring of pedagogic discourse. Routledge.

Cates, K. (1990). Teaching for a better world: Global issues in language education. The Language Teacher, 14(5), 3-5.

Davison, C. (2004). The contradictory culture of teacher-based assessment: ESL teacher assessment practices in Australian and Hong Kong secondary schools. Language Testing, 21(3), 305-334.

Flowers, N., Bernbaum, M., Rudelius-Palmer, K. \& Tolman, J. (2000). The Human Rights Education Handbook: Effective Practices for Learning, Action and Change. The United States: Human Rights Resource Center, University of Minnesota.

Freebody, P. (2007). Literacy Education in School: Research perspectives from the past, for the future. Camberwell, Victoria.

Halliday, M. A. K. \& Matthiessen, M. I. M. C. (2014). An Introduction to Functional Grammar. Arnold.

Herrera Torres, D. M. (2012). Children as subjects with rights in EFL textbooks. Colombian Applied Linguistics Journal, 14(1), 45-59. 
Kress, G. \& van Leeuwen, T. (2006). Reading Images: The Grammar of Visual Design ( $2^{\text {nd }}$ ed.). Routledge.

Kukovec, M. (2017). Human Rights Education in Foreign Language Learning. English Language Overseas Perspectives and Enquiries, 14(1), 13-24.

MacDonald, S. (1994). Professional academic writing in the Humanities and Social Sciences. Southern Illinois University Press.

Mahboob, A. (2009). English as an Islamic language: A case study of Pakistani English. World Englishes, 28(2), 175-189.

Mahboob, A. (2015). Identity management, language variation and English language textbooks: Focus on Pakistan. Language and Identity across Modes of Communication, 6, 153.

Maton, K. (2014). Knowledge and Knowers: Towards a realist sociology of education. Routledge.

Nan-Zhao, Z. (2005). Four 'Pillars of Learning' for the Reorientation and Reorganisation of Curriculum: Reflections and Discussions. International Bureau of Education-UNESCO.

O’Tool, M. (1994). The Language of Displayed Art. Leicester University Press.

Piller, I. (2010). Intercultural communication: A critical introduction. Edinburgh University Press.

Rolls, N. (2013). Literacy and social responsibility: Multiple perspectives [Book Review]. Australian Review of Applied Linguistics, 36(2), 226-229.

Schleppegrell, M. J. (2004). The language of schooling: A functional linguistics perspective. Lawrence Erlbaum.

Struthers, A. (2014). Human rights education: Educating about, through and for Human Rights. The International Journal of Human Rights, 19(1) 53-73. doi:10.1080/13642987.2014.986652.

Starkey, H. (2002). Democratic citizenship, languages, diversity and human rights. The Open University.

Totten, S., \& Pedersen, J. (Eds.). (2011). Teaching and studying social issues: Major programs and approaches. Information Age Publishing.

Zolkos, M. (2006). How to recapture human rights within the political: Validating the discourse theory approach. Human Rights and Human Welfare, 6, 43-52.

\section{Citation of this Article:}

Tehseem, T. Bokhari, Z., \& Zulfiqar, S. (2020). Human rights education and language learning in Pakistan: An EFL perspective. Journal of Education and Educational Development. 7(2), 216-243. 